\title{
Volatility and Causality in Asia Pacific Financial Markets
}

\section{Enzo Weber*}

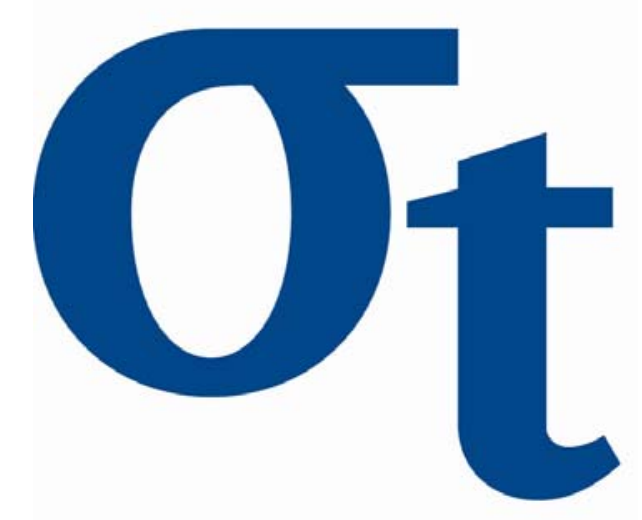

* Freie Universität Berlin, Germany $\underline{v}$

u

$\bar{\Upsilon}$

$\cup$

$\Sigma$
$\Sigma$
0
$z$
0
$U$
$\Psi$

9)

寸

6

m

느

U

This research was supported by the Deutsche Forschungsgemeinschaft through the SFB 649 "Economic Risk".

http://sfb649. wiwi.hu-berlin.de ISSN 1860-5664

SFB 649, Humboldt-Universität zu Berlin

Spandauer Straße 1, D-10178 Berlin 


\title{
Volatility and Causality in Asia Pacific Financial Markets ${ }^{1}$
}

\author{
Enzo Weber \\ Institut für Statistik und Ökonometrie, Freie Universität Berlin \\ Boltzmannstr. 20, 14195 Berlin, Germany \\ eweber@wiwiss.fu-berlin.de \\ phone: +49 30 838-55792 fax: +49 30 838-54142
}

First version: 11/2006

This version: $01 / 2007$

\begin{abstract}
The present paper analyses interactions between the foreign exchange, money and stock markets in Asian Pacific countries from 1999 till 2006. Considering influences on financial market volatility, the estimations are carried out in multivariate EGARCH models using structural residuals. This approach consequently allows the identification of the contemporaneous effects between the variables. Structural VARs or VECMs can therefore give answers to questions of exchange rate stabilisation, monetary policy behaviour or equity market reagibility. Additionally, a correlation analysis of the identified innovations reveals the degree of coherence in the Asian Pacific region.
\end{abstract}

Keywords: Structural EGARCH, Financial Markets, Asia Pacific

JEL classification: C32, G15

\footnotetext{
${ }^{1}$ This research was supported by the Deutsche Forschungsgemeinschaft through the CRC 649 "Economic Risk". I am grateful to Jürgen Wolters and Cordelia Thielitz for their support. Of course, all remaining errors are my own.
} 


\section{Introduction}

This present paper aims at identifying the impacts between key financial markets in the Asian Pacific region. More specifically, the focus is on determining causal interlinkages between daily data of the exchange rate, the money market rate and the stock index in the post-crisis period 1999-2006. The markets concerned are characterised by the absence of serious barriers and frictions, so that reactions to economic news and mutual influences are taking place even within the same day. This short time window brings the need of a thorough understanding of the structural interdependence to the fore. For the same reasons, my empirical approach also takes volatility effects into account, which play an important role for the functioning of financial systems.

Most prominently, the Asian financial crisis in 1997/98 has brought topics such as contagion and volatility transmission on the agenda. The years since then have witnessed a fast economic recovery in some countries as well as the establishment of policy concepts directed at fostering financial stability. The task of constructing a sound system of financial markets has reached high priority in international politics. Therefore, it is as well the more stable periods, which call for a better understanding of the short-run interactions between different financial assets. For example, identifying the relevant effects is crucial for conducting monetary policy in a solid and foresighted fashion. By the same token, organising the currency management especially in South-East Asia, a frequently discussed question, deserves detailed information on the mechanisms of shock propagation. Another important task, building regional capital markets for efficient factor allocation and stable development, depends on the role of stock exchanges in receiving and generating economic signals.

For establishing direct effects in the conditional mean of the three above mentioned variables, exchange rate, short-term interest rate and stock index, I first estimate reducedform time series models, thereby taking regard of possible cointegrating relations. The heteroscedasticity in the residuals is then picked up in multivariate exponential generalised autoregressive conditional heteroscedasticity (EGARCH) models. In the conventional approach, these models are specified for the reduced-form residuals, which can be seen as linear combinations of underlying structural shocks. In contrast, my methodology addresses directly the conditional variances of these structural innovations, thereby giving a solution to the problem of identifying the mutual contemporaneous impacts between the variables. This enables me to estimate structural-form mean equations in the last step without imposing constraints on the parameters, all of which are necessarily questionable 
in any financial markets context.

Concerning the relevant methodological literature, Rigobon and Sack (2003b) have recently proposed a related variant of structural GARCH, see as well Lee (2006) for an application to Asian and US stock markets. While these authors still estimated a GARCH with reduced-form residuals, even if characterised by structural restrictions, I consider directly the variance process of the structural residuals. Furthermore, I incorporate the EGARCH approach, which has been developed by Nelson (1991) in its univariate form. In this, I provide a solution to the common problem of assuring the covariance matrix to be positive definite and additionally allow for asymmetries. Moreover in contrast to the existing literature, in determining the various market interrelations, I take the contemporaneous and dynamic effects into account.

From an economic point of view, the underlying paper is related to several strands of literature analysing various possible impacts between the relevant financial variables: Perhaps most prominently, monetary reaction functions have gained attention in empirical economics. While explanatory variables like output gaps or inflation are most common, the roles of the exchange rates and share prices are far less explored and moreover highly controversial in practical monetary policy. Questions of exchange rate determination have for example been discussed in the context of the management of currency systems. Finally, the stock market performance has commonly been considered under the aspects of news effects and contagion. For recent examinations see e.g. Rigobon and Sack (2003a), Caporale, Cipollini and Demetriades (2005), Rigobon and Sack (2003b), Andersen, Bollerslev, Diebold and Vega (2005) or Bautista (2003).

The research paper is structured in the following way: The subsequent section discusses theoretical approaches on cross-effects between the three financial markets. Thereafter, section 3 introduces the methodology of structural EGARCH estimation. The empirical results of the application on the Asian Pacific region can be found in section 4, which is followed by a correlation analysis of regional coherence. The last section provides a summary and concluding considerations.

\section{Economic Foundation}

The following paragraphs give economic explanations for the most appealing influences between the exchange rate, the money market rate and the stock index. In different fields of research various specialised theoretical concepts have been developed. Eventu- 
ally though, all markets naturally follow the rules of supply and demand, so that every theoretical foundation should come across along these lines:

\section{Foreign exchange market}

In the macroeconomic theory, the most common effect is surely the exchange rate reaction to capital in- and outflows. Thereby, these movements can be induced by monetary policy decisions on the interest rate or by exogenous shifts in preferences, investment opportunities and such. While a successful interest tightening by the central bank should go along with an appreciating currency, on the contrary interest rates driven up by exogenous capital outflows are typically accompanied by depreciations. Especially for times of economic disturbances the former effect, and therefore the effectiveness of currency policy, has been doubted (Stiglitz 1999 amongst others): When interest rates push up capital costs, this increases the danger of bankruptcies of highly leveraged borrowers and might consequently provoke the phenomenon of capital flight. Another channel, which could make an interest increase fail to appreciate the currency, is inflation expectations: If a monetary policy decision is taken as carrying information on future inflation, this signal might cause an anticipated depreciation.

Concerning the equity market influences, at first one should consider the role of stocks as growth indicators: Reflecting expectations about the value of future cash-flows, they could work as signals for the performance of the economy, thus normally appreciating the exchange rate in case of "good" news. Furthermore, international portfolio shifts in reaction to stock market events cause demand respectively supply changes of the involved currencies.

\section{Money market}

Interest rate movements can generally be characterised either as policy-driven or as market-driven (e.g. Caporale, Cipollini and Demetriades 2005). On the one side, for instance a currency depreciation is likely to make the central bank thinking about raising the monetary policy rate. Obviously, this cannot happen on a day-to-day basis, but the very expectation will be projected immediately in the market. On the contrary side, the uncovered interest rate parity (UIP) provides a market linkage between interest and exchange rates: Differentials between foreign and domestic rates should be offset by an expected revaluation, in addition to a possible risk premium. Though, this already implies, that the direction of reactions depends on the mechanism of expectation formation: For example, according to adaptive expectations, a depreciation would be followed by further depreciations, while the contrary would be true for constant expectations. The effects from the stock market can be structured in a similar way: Although normally 
denied, equity developments have a signalling function for the monetary policy. Herein, I consider the channels of changes in wealth respectively consumption, of corporate investment costs and again of growth indication (e.g. Rigobon and Sack 2003a). Another mechanism probably works through the tendency of investors to switch to relatively safe bonds or money market assets in times of economic difficulties.

\section{Stock market}

Impacts on the equity index naturally are propagated through the formation of expectations, but remain theoretically indefinite in their overall direction: Taking the example of a currency depreciation, the fear of capital outflows and monetary tightening would have a negative influence on the equity performance. Notwithstanding, hopes of strengthening exports or rising retail prices would produce the contrary result. At last the concept of UIP can as well be applied to equity returns (URP: "uncovered equity return parity", see Cappiello and De Santis 2005), with the same decisive role of the form of expectations. Theories on stock market reactions to interest rate movements have been worked out relatively well (e.g. Andersen, Bollerslev, Diebold and Vega 2005). Straightforward channels can be established by defining the stock price as the sum of discounted future cash-flows: On the one hand, a negative impact comes through the interest rate reflecting opportunity and investment costs. On the other hand, interest rates contain signals of future economic growth, thereby raising expected profits hand in hand with the equity index. In the literature, theoretical and empirical results seem to favour the view, that the former effect dominates during economic upswings, while the latter, unfortunately in the reverse direction, is more important in recessions (e.g. Andersen, Bollerslev, Diebold and Vega 2005 or Boyd, Hu and Jagannathan 2005). Of course, besides signals about growth, the interest rate could as well carry information about future inflation, for example as in the Fisher equation, and the course of monetary policy. The related impact is straightforward as explained above.

Obviously, not all mentioned effects can be of the same importance in every country model. In the particular context of post-crisis Asian-Pacific financial markets the focus should be on the following points:

- Does monetary policy try to stabilise the currency?

- Can it succeed in this attempt?

- How important are exchange rate stability and interest rate movements for the overall economic performance? 


\section{Volatility effects}

Up to now, the argumentation has aimed at interrelations between the levels of the three financial variables. In general, all these connections could as well be thought of in the domain of variability, but here the theoretical foundation is rather poor. Nevertheless, volatility transmission matters for monetary policy decisions, the construction of stable financial systems, risk hedging or the reduction of vulnerability, amongst others. Therefore, on this stage I present some stylised facts, which could possibly be found in the empirical analysis:

- Concerning the exchange rate, one main question is, whether higher variability is brought into an economy by foreign linkages. Might currency revaluations for example cause speculations about central bank decisions, or does the stock market show signs of increased activity?

- Put it the other way round, does monetary policy itself induce fluctuations, as it is claimed by neoclassical theories?

- At last, in how far are contagion effects from the traditionally volatile stock market existing?

\section{Methodological Proceeding}

\subsection{Models for the Mean Process}

The basic generating process of the data (here exchange rate, money market rate and stock index) in the econometric procedure is assumed to be the structural-form VAR with lag length $q+1$

$$
A y_{t}=\mu_{0}^{*}+\mu_{1}^{*} t+\mu_{2} d_{t}+\sum_{j=1}^{q+1} B_{j}^{*} y_{t-j}+\varepsilon_{t},
$$

where $y_{t}$ contains the $n$ (here 3 ) endogenous variables, $B_{j}^{*}$ are $n \times n$ coefficient matrices and $\varepsilon_{t}$ is an $n$-dimensional vector of uncorrelated heteroscedastic residuals. The deterministic terms are a constant, a linear trend $(t)$ and centred daily seasonal dummies $\left(d_{t}\right)$, which control for possible day-of-the-week effects.

Given the presence of unit roots in the data, according to Johansen (1995), the commonness of $n-r$ stochastic trends is reflected by a reduced rank of $B^{*}(1)$, with $B^{*}(L)=$

$A-\sum_{i=1}^{q+1} B_{j}^{*} L^{j}$. Consequently, one can write $B^{*}(1)=-\alpha \beta^{\prime}$, where $\beta$ spans the space of the $r$ cointegrating vectors, and $\alpha$ contains the corresponding adjustment coefficients. 
Granger's representation theorem then leads to the structural VECM

$$
A \Delta y_{t}=\alpha\left[\beta^{\prime} y_{t-1}+\mu_{0}+\mu_{1}(t-1)\right]+\mu_{2} d_{t}+\sum_{j=1}^{q} B_{j} \Delta y_{t-j}+\varepsilon_{t},
$$

with $B_{j}=-\sum_{k=j+1}^{q+1} B_{k}^{*}, j=1, \ldots, q$. Constant and trend are assumed to be absorbed in the cointegrating relation.

Since (2) for itself is not identified, the reduced-form VECM is derived:

$$
\Delta y_{t}=\alpha^{r}\left[\beta^{\prime} y_{t-1}+\mu_{0}+\mu_{1}(t-1)\right]+\mu_{2}^{r} d_{t}+\sum_{j=1}^{q} B_{j}^{r} \Delta y_{t-j}+u_{t} .
$$

All coefficients are obtained by premultiplying $A^{-1}$ in (2), therefore being marked by the superscript $r$ for "reduced". Accordingly, the new residuals are given by $u_{t}=A^{-1} \varepsilon_{t}$.

The unit root behaviour of the series is checked by the standard ADF test (see e.g. Dickey and Fuller 1979), including a constant, a trend and centred seasonal dummies. Here, as well as in all subsequent models, the lag length is set following the usual information criteria (maximum lag 10) and autocorrelation tests. Simulated critical values for the null hypothesis of non-stationarity are taken from MacKinnon $(1991,1996)$.

For finding out the number of common stochastic trends, Johansen $(1994,1995)$ provides the likelihood ratio trace test. The test statistic for the null hypothesis of at most $r$ cointegrating relations is given by:

$$
\Lambda(r)=-T \sum_{j=r+1}^{n} \log \left(1-\hat{\lambda}_{j}\right)
$$

where $n$ is the number of endogenous variables and $T$ the number of observations. $\hat{\lambda}_{j}$ denotes the j-th largest squared sample canonical correlation between $\Delta y_{t}$ and the respective cointegrating relation, both corrected for the influence of the remaining regressors. Critical values are obtained by computing the response surface in Doornik (1998).

In case even $r=0$ is not rejected, equations (2) and (3) are specified without any cointegration terms, simply leaving VARs in first differences. Consequently, constant and trend are then considered outside the cointegrating relations.

\subsection{Identification through Heteroscedasticity}

In the structural VAR equation (1), the matrix $A$ of contemporaneous effects cannot be identified without further constraints. The theoretical considerations in section 2 found 
reasons for various possible effects between all variables and therefore did not justify any zero restrictions. By the same token, it proves impossible to recover the structural parameters from the reduced form given by (2): In the matrix $A$ with normalised diagonal, $n(n-1)$ simultaneous impacts have to be estimated, but due to its symmetry the covariance-matrix of the reduced-form residuals delivers only $n(n-1) / 2$ equations for simultaneous covariances.

In spite of reducing the number of parameters by restrictions, the present approach aims on principle at augmenting the number of determining equations (see Rigobon 2003): If one can identify for example several regimes with differing volatility, the necessary shifts in the covariance-matrix yield additional equations for uncovering the structural parameters, which for their part have to be assumed constant over time.

The next section describes the set-up and estimation of a so-called "structural GARCH" model. In this, I follow basically the intuition of identification through volatility regimes. Estimating a multivariate GARCH however is equal to modelling a continuum of regimes, which is reflected in the estimated variance processes.

\subsection{Structural EGARCH}

Since the variance model shall be specified for the structural residuals, according to (3), these are recovered by

$$
\varepsilon_{t}=A u_{t}
$$

Furthermore, define the conditional variances of the elements in $\varepsilon_{t}$ by

$$
\operatorname{Var}\left(\varepsilon_{j t} \mid I_{t-1}\right)=\operatorname{Var}_{t-1}\left(\varepsilon_{j t}\right)=h_{j t} \quad j=1, \ldots, n
$$

where $I_{t-1}$ denotes the whole set of available information at time $t-1$. The conditional covariances of the structural residuals are assumed to be zero, what is in analogy to the standard identifying procedure.

Then, stack the $h_{j t}$ in the vector $H_{t}=\left(\begin{array}{llll}h_{1 t} & h_{2 t} & \ldots & h_{n t}\end{array}\right)^{\prime}$.

At last, denote the standardised white noise residuals by

$$
\tilde{\varepsilon}_{j t}=\varepsilon_{j t} / \sqrt{h_{j t}} \quad j=1, \ldots, n .
$$

The multivariate EGARCH(1,1)-process is then given by

$$
\log H_{t}=C+G \log H_{t-1}+D\left|\tilde{\varepsilon}_{t-1}\right|+F \tilde{\varepsilon}_{t-1},
$$


where $C$ is an $n \times 1$ vector of constants, and $G, D$ and $F$ are $n \times n$ coefficient matrices. The absolute value operation is to be applied element by element.

The univariate EGARCH has been proposed by Nelson (1991). With the conditional covariances of the structural residuals assumed to be zero, the multivariate extension (8) only comprises the conditional variances. By taking logarithms, the EGARCH model guarantees these variances to be positive. Together with the zero correlations assumption, this is sufficient for positive definite covariance matrices. Furthermore, asymmetric effects are incorporated by including $\tilde{\varepsilon}_{t}$ without taking absolute values: Any parameters in $F$ differing from zero indicate, that besides the magnitude of a shock its sign contains valuable information for forecasting the conditional variances. $\operatorname{EGARCH}(1,1)$ seems to be appropriate for most series, what will be shown by Lagrange Multiplier (LM) GARCH-tests, has additionally been checked in univariate models and is quite usual in financial econometrics. Apart from that, higher-order lags would considerably complicate the likelihood optimisation.

Let $\Sigma_{t}$ denote the conditional covariance-matrix of $\varepsilon_{t}$ including the $h_{j t}$ on the main diagonal and zeros off-diagonal. Then the log-likelihood under the assumption of conditional normality results as

$$
L(A, C, G, D, F)=L(\theta)=\sum_{t=1}^{T} \log l_{t}(\theta)=-\frac{1}{2} \sum_{t=1}^{T}\left(n \log 2 \pi+\log \left|\Sigma_{t}\right|+\tilde{\varepsilon}_{t}^{\prime} \tilde{\varepsilon}_{t}\right) .
$$

Since assuming conditional normality is often problematic using financial markets data, the estimation relies on Quasi-Maximum-Likelihood (Bollerslev and Wooldridge 1992). While excess kurtosis may be taken as an argument for adopting in example a Student-tdistribution, QML has the advantage of consistency even if the distributional assumption is violated. Although consistency and asymptotic normality are not proven for my particular model, results from the MGARCH literature suggest, that

$$
\sqrt{T}(\hat{\theta}-\theta) \stackrel{d}{\rightarrow} N\left(0, M_{1}^{-1} M_{0} M_{1}^{-1}\right)
$$

where $M_{1}=-E\left(\frac{\partial^{2} \log l_{t}(\theta)}{\partial \theta \partial \theta^{\prime}}\right)$ and $M_{0}=E\left(\frac{\partial \log l_{t}(\theta)}{\partial \theta} \frac{\partial \log l_{t}(\theta)}{\partial \theta^{\prime}}\right)$ (see Comte and Lieberman 2003). Note, that the usual ML covariance matrix estimator $\hat{M}_{1}^{-1}$ would not be consistent under non-normality.

The likelihood optimisation is done using the BHHH algorithm (Berndt, Hall, Hall and Hausman 1974) in the Gauss Maxlik procedure, the code is written by the author. The parameter starting values are obtained from the univariate EGARCH estimates, the structural and cross-effect coefficients are set to zero, and the variance process is started at 
the sample moments. The choice of the starting values did not prove crucial, supported by the common result in the multivariate GARCH literature, that in any case most crosscoefficients are insignificant.

\subsection{Combining Reduced-Form and Structural Estimates}

In the first two steps, the reduced form (3) and the structural EGARCH (8) have been estimated. At last, the obtained $A$-matrix is substituted in equation (2), which is then reestimated to gain values and standard errors of the remaining parameters. This procedure allows the determination of dynamic effects running over a certain time span in addition to the contemporaneous impacts from the identified structural matrix.

In order to present a measure of the overall interaction between the variables, I compute the matrix of total effects, which are reached after the adjustment processes have been completely finished. For VARs in first differences, the long-run level impacts are given as elements of

$$
\Xi=\left(A-\sum_{j=1}^{q} B_{j}\right)^{-1}
$$

For the cointegrating models, the matrix can be derived from the VECM moving average representation (Johansen 1995):

$$
\Xi=\beta_{\perp}\left(\alpha_{\perp}^{\prime}\left(A-\sum_{j=1}^{q} B_{j}\right) \beta_{\perp}\right)^{-1} \alpha_{\perp}^{\prime},
$$

with $\perp$ denoting the orthogonal complement (thus $\alpha^{\prime} \alpha_{\perp}=0$, where both $\alpha$ and $\alpha_{\perp}$ have full column rank).

\section{Empirical Evidence}

\subsection{Data}

This study employs the common representative daily data for the foreign exchange, money and stock markets: the exchange rates $e$ measured in domestic currency units per US dollar, the three-month money market rates $i$ (short-term government bonds, where not available) and the main national stock indices $s$. The money market rate at the short end of the yield curve should be close enough to monetary policy decisions on the one hand, 
but should at the same time exhibit sufficient continuous market-driven variation on the other.

The sample from 01/04/1999 till 10/09/2006 covers the years since the Asian financial crisis in 1997/98. The countries are Australia, Hong Kong (Special Administrative Region of China), India, Indonesia, Japan, New Zealand, the Philippines, Singapore, South Korea ("Korea" in the following), Taiwan and Thailand. The interesting cases of China and Malaysia had to be left out, because their highly regulated interest and exchange rates are not suitable for an application of time series techniques. Figure 1 gives an overview of the time series; the three cases with shortened line graphs are due to scarce data availability.

In the foreign exchange market, most currencies depreciated moderately against the US dollar until 2001/2002, then appreciation sets in. For the interest rates, the same pattern could be dismantled: Normally falling till about 2003, an upturn can be detected afterwards. In the same period, the equity indices show clear signs of a stock exchange rallying. Obviously, these developments are directed by the course of the business cycle: Immediately after the crisis, the making up generated a growth peak, but the following recession in the world economy did not spare the Asian Pacific region. Though, a profound recovery seems to take place at the latest since 2003 .

For the empirical analysis, the exchange rates and the stock indices are transformed to logarithms multiplied by 100 . Then, taking first differences generates continuously compounded asset returns or growth rates in percentage points. As the interest rates are already measured in percentage points and normally remain rather low, no transformation is applied. Nonetheless, it is necessary to proceed with care in the parameter interpretation: For example, a rise of one in an annualised interest rate is equal to four standard discount rate steps of a central bank, which would be a tremendous change in contrast to a daily stock return of one percent.

Tackling the degree of persistence in the data, Table 1 displays the p-values of the ADFtests on the chosen series E, I and S, where the former and the latter are in logs as told above. The hypotheses of non-stationarity are confirmed, and additionally, the first differences are clearly $\mathrm{I}(0)$. Solely the unit root results for the Philippine interest rate are unclear, even through several tests. I will treat it conformable as an I(1)-variable, therefore naturally running the risk of over-differencing, but avoiding unbalanced regressions. The calculations in this paper have been done in Gauss 8.0, JMulti 4.14 and EViews 5.0. 



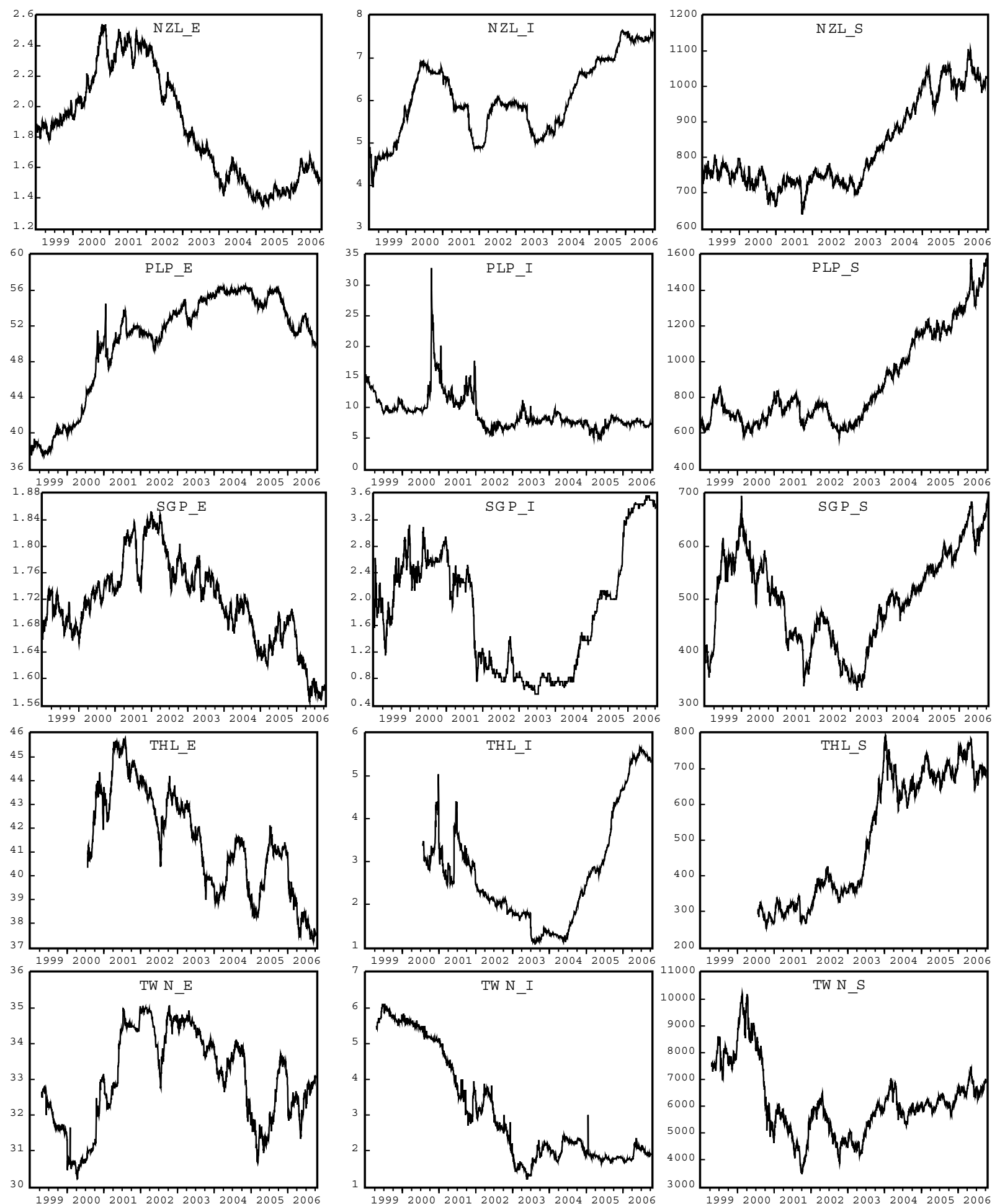

Figure 1: Exchange rates (E), money market rates (I) and stock indices (S) 


\begin{tabular}{|c|c|c|c|c|c|c|c|c|c|c|c|}
\hline & AUS & HK & IDN & INDIA & JPN & KOR & NZL & PLP & SGP & THL & TWN \\
\hline E & 0.79 & 0.20 & 0.44 & 0.78 & 0.55 & 0.83 & 0.71 & 0.97 & 0.46 & 0.06 & 0.86 \\
[lags $]$ & 0 & 0 & 0 & 0 & 0 & 1 & 0 & 0 & 0 & 0 & 1 \\
\hline I & 0.82 & 0.73 & 0.56 & 0.53 & 0.61 & 0.71 & 0.92 & 0.01 & 0.84 & 0.96 & 0.64 \\
[lags $]$ & 2 & 1 & 0 & 0 & 1 & 1 & 0 & 8 & 0 & 3 & 3 \\
\hline S & 0.89 & 0.83 & 0.93 & 0.94 & 0.96 & 0.66 & 0.52 & 0.82 & 0.91 & 0.76 \\
[lags $]$ & 0 & 0 & 1 & 1 & 0 & 0 & 0 & 1 & 0 & 0 & 0.78 \\
0
\end{tabular}

Table 1: p-values of ADF-tests

\subsection{Specification of the Reduced-Form Models}

In order to find acceptable specifications of the reduced-form VECM in (3), the numbers of lags and of cointegrating relations have to be determined. The former are chosen by the usual information criteria and are checked by LM tests (see Doornik 1996) with the null hypothesis of no autocorrelation, see Table 2. While the overall impression is quite satisfying, several rejections appear especially for the higher order. Nevertheless, for the most part of the variables, the serial correlation should be completely captured.

\begin{tabular}{|c|c|c|c|c|c|c|c|c|c|c|c|}
\hline & AUS & HK & IDN & INDIA & JPN & KOR & NZL & PLP & SGP & THL & TWN \\
\hline LM $(1)$ & 0.09 & 0.04 & 0.72 & 0.75 & 0.33 & 0.17 & 0.37 & 0.31 & 0.03 & 0.83 & 0.88 \\
\hline LM(5) & 0.28 & 0.13 & 0.35 & 0.01 & 0.11 & 0.00 & 0.02 & 0.00 & 0.02 & 0.17 & 0.60 \\
\hline lags & 2 & 2 & 5 & 1 & 3 & 1 & 1 & 2 & 1 & 3 & 5 \\
\hline
\end{tabular}

Table 2: p-values of LM-tests for no residual autocorrelation

Concerning the cointegration properties, Table 3 shows the p-values for the trace tests between the interest rates and the stock indices in bivariate models. Here, the exchange rates are not considered, because UIP or URP theoretically rule out any cointegrating relations, what has also been confirmed empirically in the run-up. Consequently, one common stochastic trend (plus the exchange rate trend in the trivariate system) is accepted for Japan, Korea and New Zealand. It is true, that the former does not yield clear significance, but the resulting VECM proved very robust and sensible, contrasting for example with a similar model for Taiwan. The low p-value for the Philippines is strictly due to the possible stationarity of its money market rate, therefore giving no grounds to specify a cointegration model. 


\begin{tabular}{|c|c|c|c|c|c|c|c|c|c|c|c|}
\hline & AUS & HK & IDN & INDIA & JPN & KOR & NZL & PLP & SGP & THL & TWN \\
\hline$H_{0}: r=0$ & 0.81 & 0.74 & 0.35 & 0.60 & $0.13^{*}$ & $0.00^{*}$ & $0.06^{*}$ & 0.02 & 0.16 & 0.57 & 0.14 \\
\hline \multicolumn{1}{c|}{$* H_{0}$ (no cointegration) rejected } \\
Deterministics: constant, linear trend when significant
\end{tabular}

Table 3: p-values of trace tests for cointegration between $i$ and $s$

\subsection{Financial Volatility Transmission}

While the reduced-form models have already been specified, the structural VARs and VECMs can only be estimated in the last step after the identification of the contemporaneous impact matrix. Therefore, at first the results for the generating processes of the conditional variances shall be presented, grouped by several similarities among certain models. Naturally, there are no cases with insignificant parameters on the diagonals of the first two matrices, thus showing the pure presence of ARCH effects in the data. The QML standard errors are put in parentheses below the coefficients.

The most simple variance equations arise from the estimations for Australia, Korea and Taiwan. Here, all non-diagonal elements are clearly insignificant, ruling out any causality in variance between the different variables. The only asymmetry appears as the wellknown leverage effect in the stock market, which can be found in nearly all models: The negative coefficients indicate, that negative shocks to equity prices have higher volatility impacts than positive ones.

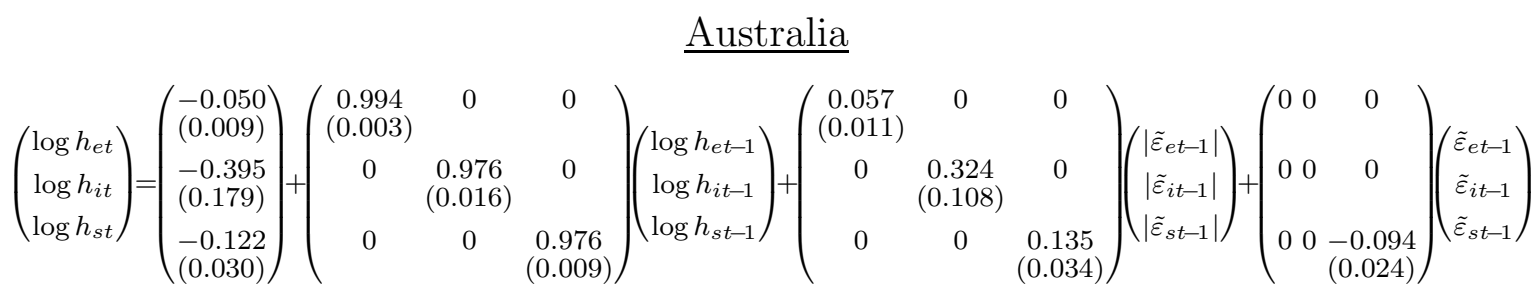

$\underline{\text { Korea }}$

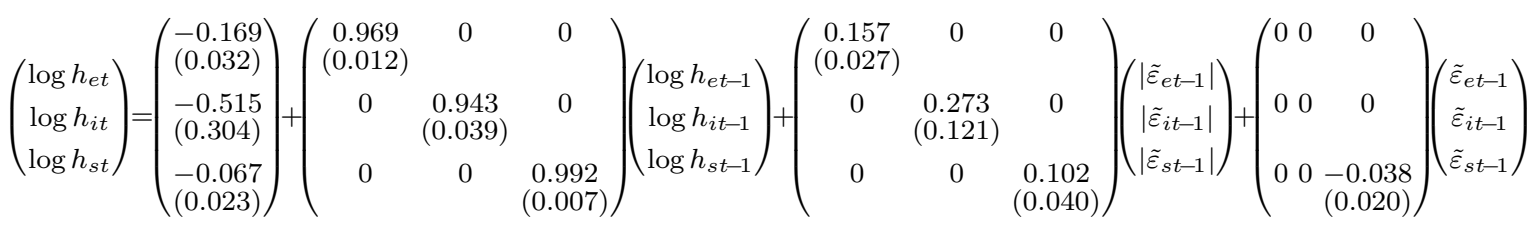

$\underline{\text { Taiwan }}$

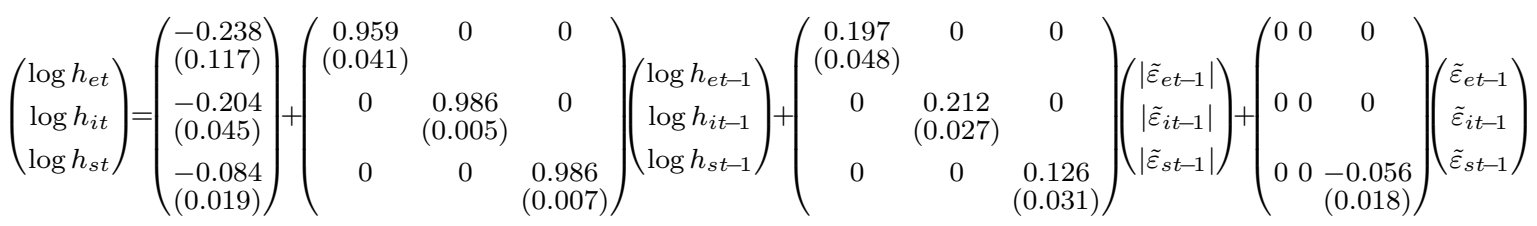


One cross-effect each can be found for New Zealand and Singapore: In New Zealand, exchange rate shocks have a considerable impact on the money market variance, what could be seen as typical for a small open economy. In Singapore, equity price shocks prove relevant for the foreign exchange market, probably explained by the role of the city state as an Asian financial centre.

$$
\begin{aligned}
& \underline{\text { New Zealand }}
\end{aligned}
$$

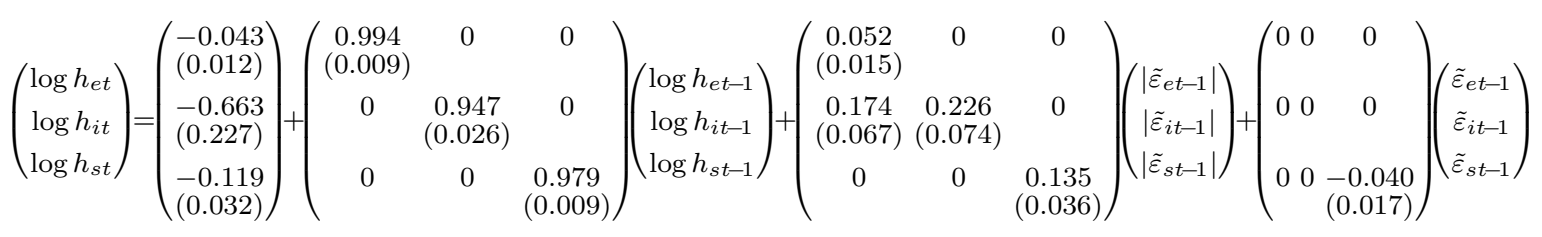

\section{Singapore}

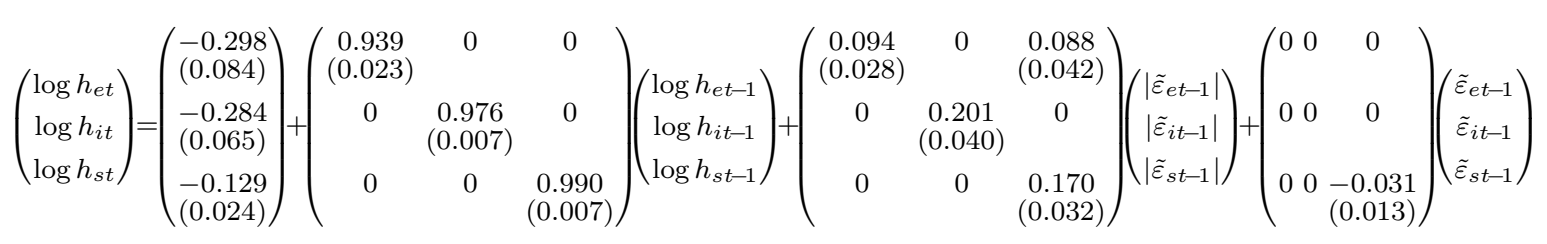

Examples well-suited to studying interactions between the foreign exchange and money markets represent Hong Kong and the Philippines. Cross-effects exist in both directions, added by asymmetric influences: In Hong Kong, appreciations push up variability in the foreign exchange and the money market, just as well as interest rate increases. Thereby, the first effect might mirror high sensitivity to losses in competitiveness, an outcome of the extraordinary export dependence of Hong Kong, as well as the need to support the quasi currency peg. Additionally, the stock market, which is of paramount importance, is surely not encouraged by rising interest rates. In contrast, for the Philippines, it is predominantly depreciations, which bring higher volatility into the money and foreign exchange markets. The same effect on the former can be found in Indonesia, typically another country with chronic instability and vulnerability. Here, additionally the stock market shocks affect the interest rate variance.

$$
\begin{aligned}
& \underline{\text { Hong Kong }}
\end{aligned}
$$

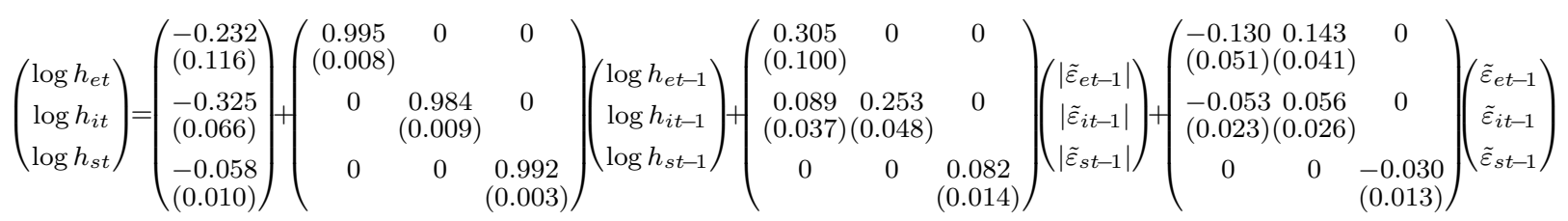




\section{Philippines}

$\left(\begin{array}{l}\log h_{e t} \\ \log h_{i t} \\ \log h_{s t}\end{array}\right)=\left(\begin{array}{c}-0.341 \\ (0.057) \\ -0.542 \\ (0.074) \\ -0.137 \\ (0.032)\end{array}\right)+\left(\begin{array}{ccc}0.982 & 0 & 0 \\ (0.010) & & \\ 0 & 0.962 & 0 \\ & (0.010) & \\ 0 & 0 & 0.944 \\ & & (0.024)\end{array}\right)\left(\begin{array}{l}\log h_{e t-1} \\ \log h_{i t-1} \\ \log h_{s t-1}\end{array}\right)+\left(\begin{array}{ccc}0.303 & 0.118 & 0 \\ (0.052)(0.046) & \\ 0.180 & 0.417 & 0 \\ (0.053)(0.059) & \\ 0 & 0 & 0.184 \\ & & (0.044)\end{array}\right)\left(\begin{array}{cc}\left|\tilde{\varepsilon}_{e t-1}\right| \\ \left|\tilde{\varepsilon}_{i t-1}\right| \\ \left|\tilde{\varepsilon}_{s t-1}\right|\end{array}\right)+\left(\begin{array}{ccc}0.066 & 0 & 0.066 \\ (0.022) & (0.028) \\ 0.089 & 0.116 & 0 \\ (0.028)(0.034) & \\ 0 & 0 & 0\end{array}\right)\left(\begin{array}{c}\tilde{\varepsilon}_{e t-1} \\ \tilde{\varepsilon}_{i t-1} \\ \tilde{\varepsilon}_{s t-1}\end{array}\right)$

\section{$\underline{\text { Indonesia }}$}

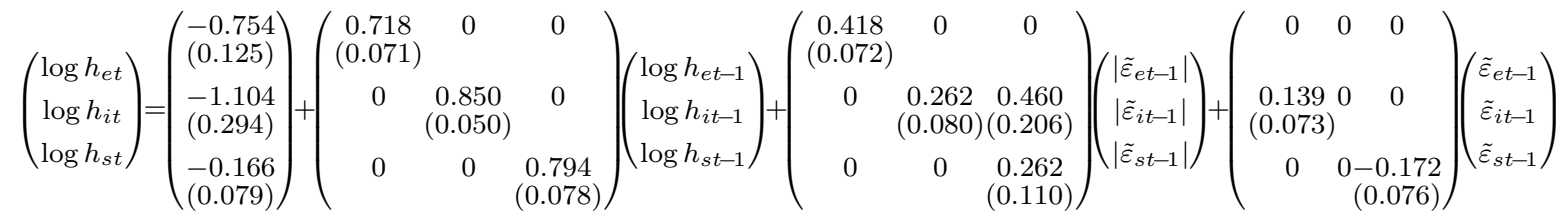

In India, falling equity prices raise the variability in the stock and foreign exchange markets. In turn, the stock index reacts to depreciating shocks, and in the money market, above all contractionary shocks drive its variance. All in all, Indian markets seem to be sensitive to reductions in the value of the respective assets. The Japanese estimated cross-effects might be interpreted against the background of the deflationary period: Positive equity shocks serve as growth signals, giving grounds to deviate from the lasting zero interest rate policy, interest rate increases reassure the foreign exchange market, and exchange rate shocks matter for stock volatility.

$$
\begin{aligned}
& \underline{\text { India }}
\end{aligned}
$$

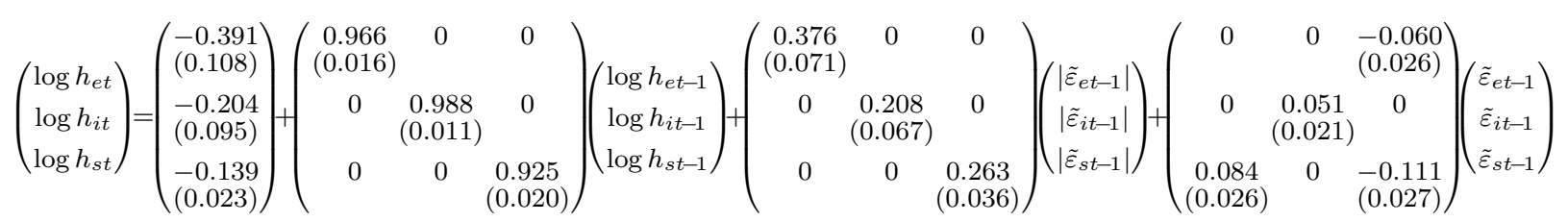

$$
\begin{gathered}
\text { Japan } \\
\left(\begin{array}{l}
\log h_{e t} \\
\log h_{i t} \\
\log h_{s t}
\end{array}\right)=\left(\begin{array}{c}
-0.062 \\
(0.020) \\
-0.385 \\
(0.095) \\
-0.132 \\
(0.023)
\end{array}\right)+\left(\begin{array}{ccc}
0.982 & 0 & 0 \\
(0.009) & & \\
0 & 0.986 & 0 \\
& (0.008) & \\
0 & 0 & 0.971 \\
& & (0.009)
\end{array}\right)\left(\begin{array}{l}
\log h_{e t-1} \\
\log h_{i t-1} \\
\log h_{s t-1}
\end{array}\right)+\left(\begin{array}{ccc}
0.056 & 0 & 0 \\
(0.018) & & \\
0 & 0.344 & 0 \\
& (0.051) & \\
0.063 & 0 & 0.130 \\
(0.026) & & (0.025)
\end{array}\right)\left(\begin{array}{l}
\left|\tilde{\varepsilon}_{e t-1}\right| \\
\left|\tilde{\varepsilon}_{i t-1}\right| \\
\left|\tilde{\varepsilon}_{s t-1}\right|
\end{array}\right)+\left(\begin{array}{ccc}
0-0.010 & 0 \\
(0.005) & \\
0 & 0 & 0.121 \\
& (0.042) \\
0 & 0 & -0.053 \\
(0.018)
\end{array}\right)\left(\begin{array}{c}
\tilde{\varepsilon}_{e t-1} \\
\tilde{\varepsilon}_{i t-1} \\
\tilde{\varepsilon}_{s t-1}
\end{array}\right)
\end{gathered}
$$

Thailand represents the only case with off-diagonal GARCH-parameters. On the one hand, variance impacts from interest rate shocks in the foreign exchange market and from the exchange rate on the equity index can be detected. On the other hand though, the corresponding autoregressive coefficients are negative, so that the effect cushions very fast in the following periods. Concerning the asymmetries, as in Hong Kong, again the strong export orientation might be responsible for appreciations and bad equity news heightening the exchange rate variability, which is anyway highly involved in the cross-dependences. 


\section{Thailand}

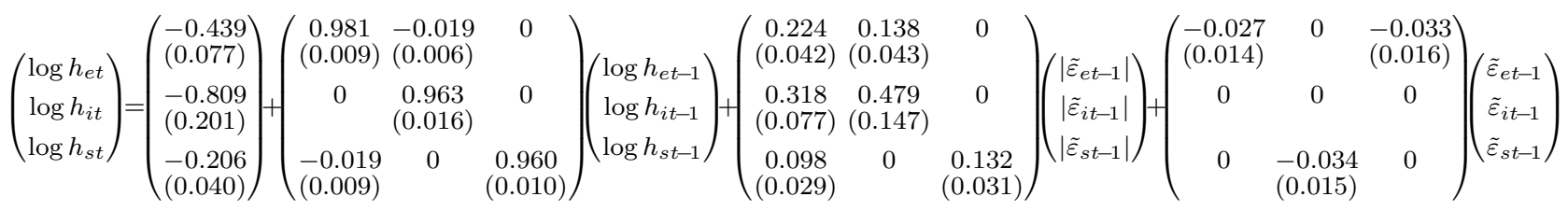

Table 4 summarises the cross-effects in variance between the different financial markets. As a first result, volatility transmission seems to appear above all in developing countries. In general, this fact can be interpreted as both source and outcome of relatively higher instability and insecurity in these economies. Recalling the initial main questions from section 2 , at first I can state, that the exchange rate indeed brings variability into the domestic economy, above all into the money market. Monetary policy induced contagion effects can be found in the exchange rate, but almost not in the stock index. In turn, fluctuations from the equity prices spill over mainly into the foreign exchange market.

\begin{tabular}{|l|l|}
\hline Effect & Countries \\
\hline exchange rate $\rightarrow$ interest rate & NZL HK + PLP - IDN- THL \\
exchange rate $\rightarrow$ stock index & INDIA - JPN THL \\
\hline interest rate $\rightarrow$ exchange rate & HK + PLP JPN - THL \\
interest rate $\rightarrow$ stock index & THL - \\
\hline stock index $\rightarrow$ exchange rate & SGP PLP + INDIA - THL- \\
stock index $\rightarrow$ interest rate & IDN JPN + \\
\hline \multicolumn{2}{|c|}{$+/-:$ Direction of asymmetry } \\
\hline
\end{tabular}

Table 4: Variance cross-effects in different countries

After presenting the results of the multivariate EGARCH estimations, I examine, if the models catch up sufficiently the heteroscedasticity in the data. The p-values for the ARCH-LM null hypothesis of no remaining ARCH in the residuals in Table 5 confirm the standard literature result, that GARCH models of orders 1,1 are appropriate for financial markets data. Given the quite considerable number of tests, several rejections should not be too problematic. Furthermore, the autoregressive parameters smaller than one meet the stability criterion; the still high persistence is a common feature throughout the ARCH literature.

The graphs of the estimated conditional variances can be found in the Appendix Figure 2. As an overall impression, the volatilities in the money and stock markets might be

\footnotetext{
${ }^{2}$ The signs for the exchange rate appear reversed, because logically a depreciation is a negative change despite the definition "domestic currency / USD".
} 


\begin{tabular}{|l|l|l|l|l|l|l|l|l|l|l|l|c|}
\hline & & AUS & HK & IDN & INDIA & JPN & KOR & NZL & PLP & SGP & THL & TWN \\
\hline \multirow{3}{*}{ LM(1) } & E & 0.16 & 0.00 & 0.79 & 0.53 & 0.61 & 0.23 & 0.93 & 0.63 & 0.12 & 0.44 & 0.22 \\
& I & 0.84 & 0.21 & 0.42 & 0.00 & 0.96 & 0.96 & 0.90 & 0.89 & 0.12 & 0.93 & 0.71 \\
& S & 0.00 & 0.05 & 0.62 & 0.84 & 0.01 & 0.48 & 0.75 & 0.72 & 0.96 & 0.36 & 0.21 \\
\hline \multirow{3}{*}{ LM(5) } & E & 0.27 & 0.00 & 0.97 & 0.82 & 0.60 & 0.73 & 0.03 & 0.76 & 0.39 & 0.61 & 0.85 \\
& I & 0.95 & 0.72 & 0.00 & 0.00 & 0.99 & 1.00 & 0.20 & 0.09 & 0.00 & 0.54 & 1.00 \\
& S & 0.03 & 0.08 & 0.62 & 0.44 & 0.01 & 0.47 & 0.49 & 0.86 & 0.25 & 0.11 & 0.22 \\
\hline
\end{tabular}

Table 5: p-values of LM-tests for no residual ARCH

slightly diminishing through time. While an economic stabilisation thus becomes evident, no such clear pattern is revealed by the exchange rate variabilities.

\subsection{Financial Markets Interlinkages}

As has already been announced, this section contains the estimations of the fundamental connections between the underlying financial markets. By maximising the likelihood function (9), besides the EGARCH parameters, estimates of the contemporaneous impacts are obtained. In the following VAR and VECM systems, the corresponding $A$ matrices are treated as given, what therefore allows the estimation of the right-hand sides of equation (2), including as well the cointegrating relations. The dots serve as placeholders for the deterministics and residuals. As a summary measure, below the respective equations, I provide the total effects $\Xi$ in the different models, which are usually reached quite quickly in financial markets.

The long-run reactions of the variables to their own structural disturbances normally lie around one. Only in the three models with cointegration (Japan, Korea, New Zealand) the middle element is near or equal to zero, because the interest rate adjusts to the longrun relation and therefore equalises all equilibrium deviations, including those produced by its own shocks. Evidently, the interest rate is then bound to follow the development of the overall economic performance revealed in the equity index. In the cases of Japan and New Zealand, the interest rates even have zero total impact on all variables, since they are the only ones adjusting to the cointegrating term. Above all, the stock prices are not influenced by long-run disequilibria, thereby supporting the efficient market hypothesis.

For the better part of cases, the reactions of the exchange rates to money and stock market shocks are straightforward: Increasing interest rates strengthen the currency, what represents the textbook effect of monetary policy. Japan and New Zealand, for which the 
total effects are zero due to cointegration, still show negative interim multipliers. The only positive values appear in Korea, Singapore and Taiwan, where targets of exchange rate control therefore may be difficult to achieve.

Good news from the stock exchange uniformly lead to an appreciation of the currency, what is in line with the role of equity prices as growth indicators. The strongest impacts are detected for Indonesia, Korea and New Zealand.

In eight countries, depreciations cause rises in the money market rates. While most dimensions remain relatively low, considerable effects exist for Hong Kong, Indonesia and the Philippines. The quasi pegging of the Hong Kong to the US dollar still comes as a natural explanation, but for the latter countries, the results cast doubts on their free floating regimes. Note however, that the UIP mechanism with adaptive expectations could produce a similar outcome.

The central bank reactions to stock market developments are indeed very weak with most parameters remaining near zero. Only for Korea and New Zealand economically relevant influences might be found, what is strictly due to the presence of cointegration in these cases.

Surprisingly, only in the two cases of Japan and New Zealand, the equity market gains from a devaluation. In the other countries, the importance of a stable currency obviously outweighs possible profits in the export sector by far. While this might be a result of the crisis experience, the Japanese deflationary environment naturally prefers depreciations, and New Zealand as a small open and stable economy benefits extensively from a weaker exchange rate.

The evidence of stock market reactions to interest rate changes is mixed: Positive impacts are established for Australia, Indonesia, Japan (largest, but only transitory), Thailand and Taiwan. For these countries, growth signals thus seem to have played a predominant role, referring to the explanations in section 2. The negative discount rate or investment cost effect can be found in Hong Kong, Korea and the Philippines. The two former are the economies with the strongest growth performance in the sample, what gives support to the theory, that the domestic effectiveness of monetary policy depends on the state of the business cycle. 


\section{$\underline{\text { Australia }}$}

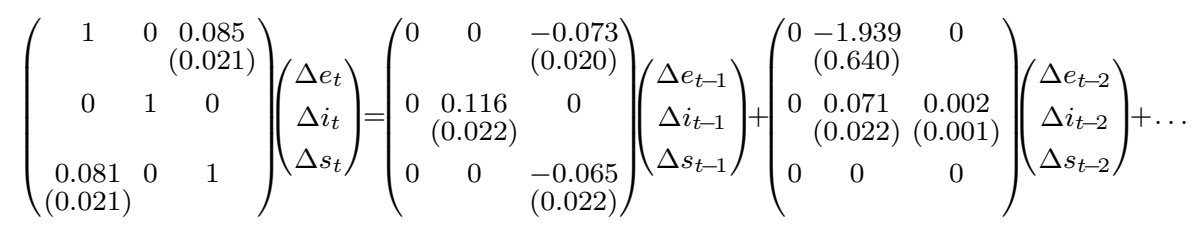

$$
\begin{aligned}
& \Xi=\left(\begin{array}{rrr}
1.013 & -2.415 & -0.155 \\
-0.000 & 1.231 & 0.002 \\
-0.077 & 0.184 & 0.951
\end{array}\right)
\end{aligned}
$$

\section{$\underline{\text { Hong Kong }}$}

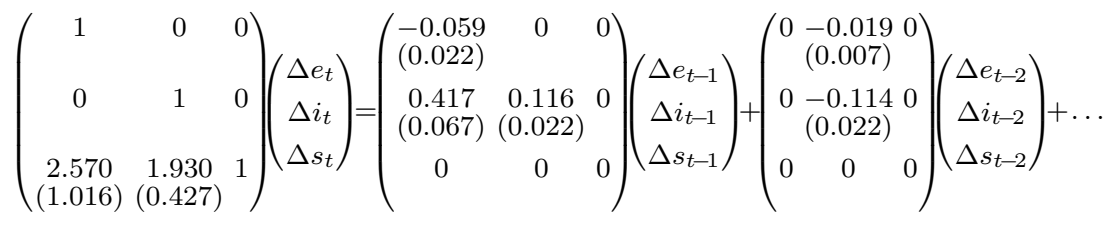

$$
\begin{aligned}
& \Xi=\left(\begin{array}{rrr}
0.937 & -0.018 & 0.000 \\
0.392 & 0.995 & 0.000 \\
-3.165 & -1.874 & 1.000
\end{array}\right)
\end{aligned}
$$

\section{$\underline{\text { Indonesia }}$}

$$
\begin{aligned}
& \left(\begin{array}{ccc}
1 & 0 & 0.143 \\
0 & 1 & 0 \\
0.567 & -0.865 & 1
\end{array}\right)\left(\begin{array}{c}
\Delta e_{t} \\
\Delta i_{t} \\
\Delta s_{t}
\end{array}\right)=\left(\begin{array}{ccc}
0 & 0 & 0 \\
0 & 0 & 0 \\
& & \\
0 & 0 & 0.130 \\
& (0.320) & (0.030)
\end{array}\right)\left(\begin{array}{c}
\Delta e_{t-1} \\
\Delta i_{t-1} \\
\Delta s_{t-1}
\end{array}\right)+\left(\begin{array}{ccc}
-0.093 & 0 & 0 \\
(0.031) & \\
0 & 0 & 0 \\
& & \\
-0.191 & 0 & -0.114 \\
(0.078) & (0.033)
\end{array}\right)\left(\begin{array}{c}
\Delta e_{t-2} \\
\Delta i_{t-2} \\
\Delta s_{t-2}
\end{array}\right) \\
& +\left(\begin{array}{ccc}
0 & 0 & -0.039 \\
0.023 & 0 & 0 \\
\left(\begin{array}{cc}
0.010) \\
0
\end{array}\right. & 0 & 0
\end{array}\right)\left(\begin{array}{l}
\Delta e_{t-3} \\
\Delta i_{t-3} \\
\Delta s_{t-3}
\end{array}\right)+\left(\begin{array}{ccc}
0 & 0 & 0 \\
0 & 0 & -0.011 \\
& & (0.004) \\
-0.170 & 0.550 & 0
\end{array}\right)\left(\begin{array}{c}
\Delta e_{t-4} \\
\Delta i_{t-4} \\
\Delta s_{t-4}
\end{array}\right)+\left(\begin{array}{ccc}
0 & 0 & 0 \\
0.071) & (0.238) &
\end{array}\right)+\left(\begin{array}{ccc}
0.031 & -0.083 & 0 \\
(0.010) & (0.033) \\
-0.324 & 0 & 0 \\
(0.071) &
\end{array}\right)\left(\begin{array}{l}
\Delta e_{t-5} \\
\Delta i_{t-5} \\
\Delta s_{t-5}
\end{array}\right)+\ldots \\
& \Xi=\left(\begin{array}{rrr}
1.144 & -0.272 & -0.209 \\
0.071 & 0.893 & -0.023 \\
-1.374 & 1.636 & 1.252
\end{array}\right)
\end{aligned}
$$

$\underline{\text { India }}$

$$
\begin{gathered}
\left(\begin{array}{ccc}
1 & 0 & 0.010 \\
0 & 1 & 0 \\
0.003) \\
0.973 & 0 & 1
\end{array}\right)\left(\begin{array}{l}
\Delta e_{t} \\
\Delta i_{t} \\
\Delta s_{t}
\end{array}\right)=\left(\begin{array}{ccc}
-0.049 & 0 & -0.006 \\
(0.022) & (0.003) \\
0 & 0 & -0.002 \\
& (0.001) \\
0 & 0 & 0.072 \\
& (0.022)
\end{array}\right)\left(\begin{array}{l}
\Delta e_{t-1} \\
\Delta i_{t-1} \\
\Delta s_{t-1}
\end{array}\right)+\ldots \\
\Xi \\
\quad=\left(\begin{array}{rrr}
0.969 & 0.000 & -0.017 \\
0.002 & 1.000 & -0.002 \\
-1.016 & 0.000 & 1.095
\end{array}\right)
\end{gathered}
$$




$$
\begin{aligned}
& \text { Japan } \\
& \left(\begin{array}{ccc}
1 & 2.769 & 0 \\
& (1.593) & \\
0 & 1 & -0.001 \\
& & (0.0001) \\
0 & -9.066 & 1 \\
(3.160) &
\end{array}\right)\left(\begin{array}{c}
\Delta e_{t} \\
\Delta i_{t} \\
\Delta s_{t}
\end{array}\right)=\left(\begin{array}{c}
0 \\
-0.005 \\
(0.001) \\
0
\end{array}\right)\left(\begin{array}{cc}
i_{t-1}-0.008 s_{t-1}+8.016-0.0003(t-1) \\
(0.003) & (3.155)(0.00009)
\end{array}\right)
\end{aligned}
$$

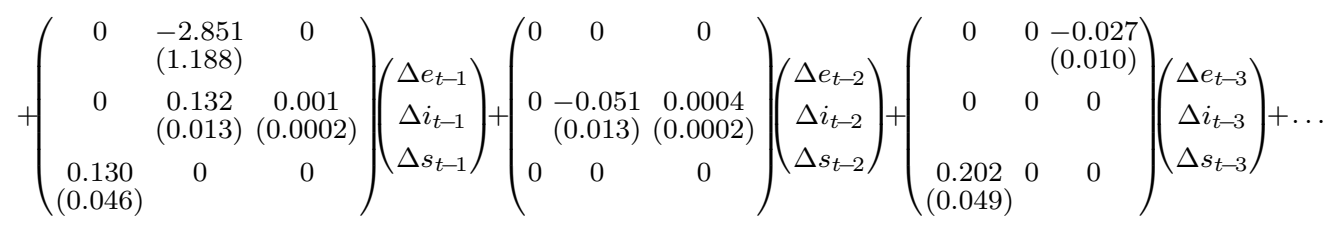

$$
\begin{aligned}
& \Xi=\left(\begin{array}{rrr}
0.975 & 0.000 & -0.076 \\
0.003 & 0.000 & 0.008 \\
0.349 & 0.000 & 1.051
\end{array}\right)
\end{aligned}
$$

\section{$\underline{\text { Korea }}$}

$$
\begin{aligned}
& \left(\begin{array}{ccc}
1 & -0.529 & 0.041 \\
0 & (0.192) & (0.006) \\
0.664 & 0 & 0 \\
(0.099) & 1 & 1
\end{array}\right)\left(\begin{array}{c}
\Delta e_{t} \\
\Delta i_{t} \\
\Delta s_{t}
\end{array}\right)=\left(\begin{array}{c}
0.04 \\
(0.013) \\
-0.008 \\
(0.002) \\
0
\end{array}\right)\left(\begin{array}{cc}
i_{t-1}-0.050 s_{t-1}+24.56+0.003(t-1) \\
(0.008) & (4.824)(0.000)
\end{array}\right)+\left(\begin{array}{ccc}
-0.097 & 0 & -0.016 \\
(0.018) & & (0.005) \\
0 & 0.192 & 0 \\
& (0.012) & \\
0 & 0 & 0
\end{array}\right)\left(\begin{array}{l}
\Delta e_{t-1} \\
\Delta i_{t-1} \\
\Delta s_{t-1}
\end{array}\right)+\ldots \\
& \Xi=\left(\begin{array}{rrr}
1.061 & 5.305 & -0.247 \\
-0.035 & -0.176 & 0.058 \\
-0.704 & -3.522 & 1.164
\end{array}\right)
\end{aligned}
$$

$\underline{\text { New Zealand }}$

$$
\begin{aligned}
& \left(\begin{array}{c}
\Delta e_{t} \\
\Delta i_{t} \\
\Delta s_{t}
\end{array}\right)=\left(\begin{array}{c}
0 \\
-0.003 \\
(0.001) \\
0
\end{array}\right)\left(\begin{array}{rr}
i_{t-1}-0.067 s_{t-1}+38.52 \\
(0.013) & (9.018)
\end{array}\right)+\left(\begin{array}{ccc}
0 & -1.193 & -0.09 \\
& (0.54) & (0.023) \\
0.003 & 0.049 & -0.003 \\
(0.001) & (0.022) & (0.001) \\
0.049 & 0 & 0 \\
(0.021) & &
\end{array}\right)\left(\begin{array}{c}
\Delta e_{t-1} \\
\Delta i_{t-1} \\
\Delta s_{t-1}
\end{array}\right)+\ldots \\
& \Xi=\left(\begin{array}{rrr}
0.992 & 0.000 & -0.169 \\
0.003 & 0.000 & 0.067 \\
0.049 & 0.000 & 0.992
\end{array}\right) \\
& \left(\begin{array}{ccc}
1 & 0 & 0.016 \\
-0.075 & 1 & 0 \\
(0.013) & & \\
0.240 & 0.237 & 1
\end{array}\right)\left(\begin{array}{c}
\Delta e_{t} \\
\Delta i_{t} \\
\Delta s_{t}
\end{array}\right)=\left(\begin{array}{ccc}
-0.056 & 0 & 0 \\
(0.123) & (0.093) &
\end{array}\right)=\left(\begin{array}{ccc}
-0.022) & \\
0.265 & 0 & 0 \\
(0.020) & & \\
0 & 0 & 0.094 \\
\Delta e_{t-1} \\
\Delta i_{t-1} \\
\Delta s_{t-1}
\end{array}\right)+\left(\begin{array}{ccc}
(0.022) & -0.128 & 0 \\
0.093 & 0.108 & 0 \\
(0.020) & (0.021) \\
-0.136 & 0 & 0 \\
(0.051) & & (0.022)
\end{array}\right)\left(\begin{array}{l}
\Delta e_{t-2} \\
\Delta i_{t-2} \\
\Delta s_{t-2}
\end{array}\right)+\ldots \\
& \Xi=\left(\begin{array}{rrr}
0.855 & -0.119 & -0.015 \\
0.415 & 1.064 & -0.007 \\
-0.464 & -0.229 & 1.112
\end{array}\right)
\end{aligned}
$$

\section{$\underline{\text { Philippines }}$}




\section{Singapore}

$$
\begin{aligned}
& \left(\begin{array}{ccc}
1 & -0.294 & 0.013 \\
-0.007 & 1 & 0 \\
(0.002) & & \\
0 & 0 & 1
\end{array}\right)\left(\begin{array}{c}
\Delta e_{t} \\
\Delta i_{t} \\
\Delta s_{t}
\end{array}\right)=\left(\begin{array}{ccc}
0 & -0.004 & -0.0002 \\
& (0.001) & (0.0001) \\
0.023 & 0 & 0 \\
(0.004) & & \\
0 & 0 & 0.001 \\
& & (0.0002)
\end{array}\right)\left(\begin{array}{l}
\Delta e_{t-1} \\
\Delta i_{t-1} \\
\Delta s_{t-1}
\end{array}\right)+\ldots \\
& \Xi=\left(\begin{array}{rrr}
1.009 & 0.293 & -0.013 \\
0.030 & 1.009 & -0.001 \\
0.000 & 0.000 & 1.001
\end{array}\right)
\end{aligned}
$$

Thailand

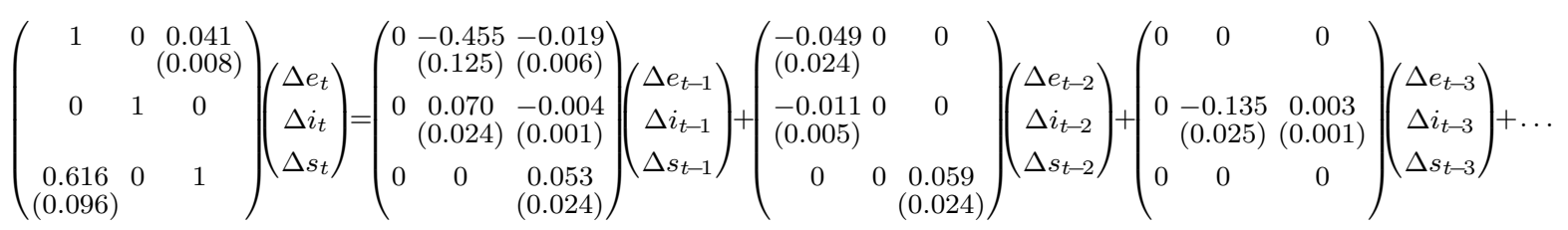

$$
\begin{aligned}
& \Xi=\left(\begin{array}{rrr}
0.997 & -0.426 & -0.067 \\
-0.010 & 0.943 & -0.001 \\
-0.692 & 0.296 & 1.173
\end{array}\right)
\end{aligned}
$$

\section{$\underline{\text { Taiwan }}$}

$$
\begin{aligned}
& \left(\begin{array}{ccc}
1 & 0 & 0.027 \\
-0.015 & 1 & -0.003 \\
(0.003) & & (0.001) \\
0.827 & -1.776 & 1
\end{array}\right)\left(\begin{array}{c}
\Delta e_{t} \\
\Delta i_{t} \\
\Delta s_{t}
\end{array}\right)=\left(\begin{array}{ccc}
-0.174 & 0 & -0.012 \\
(0.022) & & (0.004) \\
0 & -0.481 & 0.003 \\
& (0.022) & (0.001) \\
-0.125) & (0.538) &
\end{array}\right)\left(\begin{array}{ccc}
\Delta e_{t-1} \\
\Delta i_{t-1} \\
\Delta s_{t-1}
\end{array}\right)+\left(\begin{array}{ccc}
0 & 0 & -0.009 \\
(0.119) & 0 & 0
\end{array}\right)\left(\begin{array}{ccc}
0.004) \\
0.012 & -0.246 & 0.002 \\
0.005) & (0.024) & (0.001) \\
0 & 0 & 0
\end{array}\right)\left(\begin{array}{c}
\Delta e_{t-2} \\
\Delta i_{t-2} \\
\Delta s_{t-2}
\end{array}\right)
\end{aligned}
$$

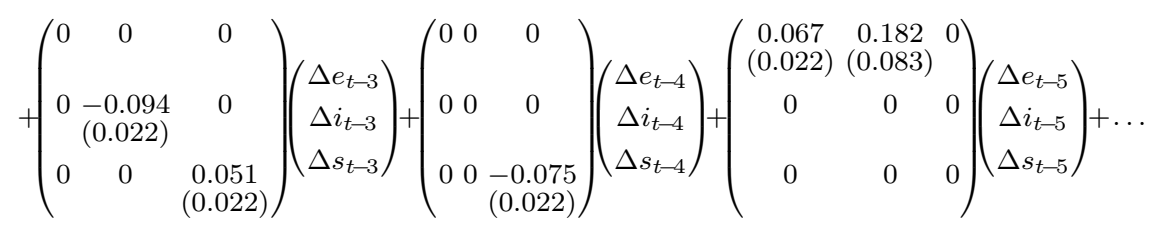

$$
\begin{aligned}
& \Xi=\left(\begin{array}{rrr}
0.951 & 0.052 & -0.044 \\
0.010 & 0.554 & 0.004 \\
-1.053 & 0.902 & 1.033
\end{array}\right)
\end{aligned}
$$

In view of the main points from section 2 , the results can be summarised as follows:

- Most countries operate a certain currency stabilisation.

- Normally, interest rate policy has the potential to succeed, but especially Korea, Singapore and Taiwan failed.

- The majority of the equity markets prefer strong stable currencies to the competition advantages from depreciations. The reaction to interest rate movements presumably depends on the state of the economy. 


\subsection{Common Regional Shocks}

Until now, I have concentrated on level and volatility effects within models for the individual countries. Naturally, the methodology can just as well be applied to estimating systems including financial variables across different economies. In this paper however, I take advantage of having identified the national economic disturbances to address regional coherence: The following correlation analysis of the structural residuals should yield information not on the causal influences among the Asian Pacific countries, but on their exposure to common shocks in the financial markets. Additionally, correlations among the conditional variances could reveal common patterns in the sequence of volatile and calm periods. This point of view gains its importance from the organisation of economic cooperation in the Asian Pacific region, when for instance, symmetric innovations are taken as prerequisites for an optimal South-East Asian currency area.

At first sight, Tables 6, 7 and 8 clarify, that relevant correlations exist only between the exchange rate $($ mean $=0.24)$ and the stock market $($ mean $=0.29)$ shocks. In contrast, the interest rate innovations (mean correlation $=0.03$ ) seem to follow strong idiosyncratic courses. Significance of the correlations is not assessed, because the high number of daily observations allows almost no discrimination.

In the foreign exchange market, exceptions from the relatively strong linkages might be Hong Kong, India, the Philippines and Taiwan; excluding these countries raises the mean correlation to 0.35 . For the former, the quasi dollar pegging comes as an obvious explanation, India does of course not fit into the group of typical South-East Asian countries, and the Philippines are characterised by an unstable economic environment with a number of outliers. Interpreting the exchange rate correlations, one has to bear in mind, that developments initiated by the US side are likely to have similar consequences on all considered currencies. While this describes a natural common factor for all exchange rates, the variances are obviously less coherent (mean correlation $=0.12$ ).

As has been mentioned above, the different money markets are not subject to relevant common shocks. Contrary results might at most be found for the Oceanic countries Australia and New Zealand as well as the cities of Hong Kong and Singapore. Evidently, the markets are not governed by arbitrage mechanisms as described by the UIP, but follow for example national monetary policy decisions. This result can be confirmed by a cointegration analysis, producing hardly any evidence for commonness of stochastic trends in the interest rates. The interpretation should nonetheless take into account, that the turnovers in some of the national markets are quite low, rendering too far-reaching 


\begin{tabular}{|c|c|c|c|c|c|c|c|c|c|c|c|}
\hline & AUS & HK & IDN & INDIA & JPN & KOR & NZL & PLP & SGP & THL & TWN \\
\hline AUS & $\times$ & 0.05 & 0.04 & 0.18 & 0.21 & -0.04 & 0.78 & 0.14 & 0.12 & 0.05 & -0.05 \\
\hline HK & 0.13 & $\times$ & -0.05 & 0.05 & -0.03 & -0.05 & -0.04 & -0.04 & -0.01 & 0.07 & 0.02 \\
\hline IDN & 0.22 & 0.10 & $\times$ & 0.17 & 0.09 & 0.10 & 0.10 & 0.25 & 0.27 & 0.13 & 0.08 \\
\hline INDIA & 0.16 & 0.16 & 0.22 & $\times$ & 0.00 & -0.01 & 0.28 & -0.07 & 0.16 & 0.18 & 0.23 \\
\hline JPN & 0.32 & 0.16 & 0.25 & 0.19 & $\times$ & 0.14 & 0.23 & -0.05 & 0.33 & 0.14 & 0.11 \\
\hline KOR & 0.16 & 0.11 & 0.30 & 0.16 & 0.32 & $\times$ & 0.03 & 0.08 & 0.34 & 0.34 & 0.24 \\
\hline NZL & 0.77 & 0.11 & 0.18 & 0.14 & 0.27 & 0.15 & $\times$ & 0.10 & 0.15 & 0.23 & 0.09 \\
\hline PLP & 0.08 & 0.03 & 0.28 & 0.07 & 0.14 & 0.20 & 0.09 & $\times$ & -0.04 & 0.07 & 0.03 \\
\hline SGP & 0.37 & 0.17 & 0.35 & 0.24 & 0.58 & 0.36 & 0.36 & 0.22 & $\times$ & 0.36 & 0.15 \\
\hline THL & 0.29 & 0.15 & 0.33 & 0.22 & 0.50 & 0.36 & 0.28 & 0.23 & 0.60 & $\times$ & 0.37 \\
\hline TWN & 0.18 & 0.08 & 0.23 & 0.17 & 0.20 & 0.35 & 0.13 & 0.13 & 0.27 & 0.28 & $\times$ \\
\hline
\end{tabular}

Table 6: Correlations of exchange rate shocks (lower left) and variances (upper right)

comparisons unreliable. The variances are correlated only slightly higher than the shocks (mean $=0.10)$, but for a cluster containing the industrialised economies of Hong Kong, Japan, Korea, New Zealand and Singapore interest rate volatility is much more symmetric (mean correlation $=0.36$ ). In contrast, the less developed markets seem to be disconnected from any regional development.

\begin{tabular}{|c|c|c|c|c|c|c|c|c|c|c|c|}
\hline & AUS & HK & IDN & INDIA & JPN & KOR & NZL & PLP & SGP & THL & TWN \\
\hline AUS & $\times$ & 0.03 & 0.02 & 0.12 & -0.03 & 0.16 & 0.24 & 0.04 & 0.17 & 0.08 & 0.02 \\
\hline HK & 0.10 & $\times$ & -0.05 & 0.21 & 0.34 & 0.28 & 0.47 & -0.02 & 0.65 & -0.00 & -0.03 \\
\hline IDN & -0.03 & 0.02 & $\times$ & -0.13 & -0.06 & 0.06 & 0.07 & -0.03 & -0.10 & 0.05 & -0.04 \\
\hline INDIA & 0.02 & 0.05 & 0.00 & $\times$ & 0.26 & 0.16 & 0.18 & 0.05 & 0.41 & 0.06 & -0.05 \\
\hline JPN & 0.03 & 0.03 & -0.01 & 0.02 & $\times$ & 0.08 & 0.26 & -0.04 & 0.42 & -0.02 & -0.11 \\
\hline KOR & 0.09 & 0.07 & 0.07 & -0.01 & -0.06 & $\times$ & 0.22 & 0.00 & 0.37 & 0.03 & 0.07 \\
\hline NZL & 0.22 & 0.06 & -0.04 & -0.01 & 0.02 & 0.04 & $\times$ & -0.02 & 0.47 & 0.03 & 0.05 \\
\hline PLP & 0.01 & 0.02 & -0.03 & -0.03 & 0.00 & -0.00 & 0.03 & $\times$ & -0.04 & 0.02 & 0.01 \\
\hline SGP & 0.07 & 0.22 & -0.05 & 0.02 & 0.01 & 0.05 & 0.05 & 0.01 & $\times$ & 0.06 & -0.00 \\
\hline THL & 0.04 & 0.07 & 0.10 & 0.04 & -0.01 & 0.03 & 0.04 & 0.06 & 0.07 & $\times$ & -0.01 \\
\hline TWN & 0.03 & 0.02 & -0.02 & -0.03 & 0.01 & 0.04 & 0.06 & 0.01 & 0.01 & 0.03 & $\times$ \\
\hline
\end{tabular}

Table 7: Correlations of interest rate shocks (lower left) and variances (upper right)

A totally different pattern can be established in the equity markets, where the most coherent innovations are found. Deviations might at best be given in pairs including 
India, New Zealand, Thailand or Taiwan; the mean correlation among the remaining countries comes to 0.37 . The high correlations between the shocks themselves are still surpassed by those among the variances (mean=0.47). While the regional countries seem to be hit by symmetric economic news on growth prospects, the trading processes in the national stock exchanges also generate similar reactions and variabilities.

\begin{tabular}{|c|c|c|c|c|c|c|c|c|c|c|c|}
\hline & AUS & HK & IDN & INDIA & JPN & KOR & NZL & PLP & SGP & THL & TWN \\
\hline AUS & $\times$ & 0.54 & 0.26 & 0.41 & 0.53 & 0.48 & 0.69 & 0.52 & 0.66 & 0.25 & 0.35 \\
\hline HK & 0.45 & $\times$ & 0.29 & 0.46 & 0.57 & 0.75 & 0.73 & 0.48 & 0.81 & 0.55 & 0.67 \\
\hline IDN & 0.34 & 0.39 & $\times$ & 0.59 & 0.31 & 0.23 & 0.21 & 0.18 & 0.30 & 0.21 & 0.32 \\
\hline INDIA & 0.21 & 0.28 & 0.34 & $\times$ & 0.36 & 0.37 & 0.49 & 0.30 & 0.43 & 0.43 & 0.31 \\
\hline JPN & 0.43 & 0.49 & 0.34 & 0.23 & $\times$ & 0.38 & 0.41 & 0.39 & 0.55 & 0.47 & 0.48 \\
\hline KOR & 0.37 & 0.50 & 0.38 & 0.25 & 0.44 & $\times$ & 0.59 & 0.42 & 0.69 & 0.44 & 0.73 \\
\hline NZL & 0.39 & 0.27 & 0.12 & 0.10 & 0.20 & 0.24 & $\times$ & 0.54 & 0.70 & 0.45 & 0.49 \\
\hline PLP & 0.30 & 0.24 & 0.21 & 0.11 & 0.24 & 0.22 & 0.21 & $\times$ & 0.57 & 0.46 & 0.42 \\
\hline SGP & 0.40 & 0.57 & 0.41 & 0.29 & 0.40 & 0.44 & 0.25 & 0.22 & $\times$ & 0.48 & 0.59 \\
\hline THL & 0.25 & 0.31 & 0.25 & 0.21 & 0.25 & 0.29 & 0.13 & 0.15 & 0.37 & $\times$ & 0.44 \\
\hline TWN & 0.24 & 0.32 & 0.33 & 0.18 & 0.28 & 0.34 & 0.15 & 0.14 & 0.30 & 0.23 & $\times$ \\
\hline
\end{tabular}

Table 8: Correlations of stock market shocks (lower left) and variances (upper right)

\section{Concluding Summary}

This paper presented the application of a new identification method in order to estimate the impacts between the foreign exchange, money and stock markets in the Asian Pacific region. In this, structural models for conditional mean and variance have been combined in a unified econometric framework. The methodology allows to obtain the causal relations underlying the pure correlations between the financial variables, and therefore leads to interpretations in the sense of relevant economic theories.

The multivariate EGARCH analysis revealed various causality-in-variance effects between the volatilities in the national financial markets. Typical examples are mutual impulses between the foreign exchange and the money markets or according reactions to stock market shocks. When thinking of constructing stable financial systems or conducting monetary policy within these systems, one should consequently be conscious about the spillovers of variability and uncertainty across different markets. 
The identification of the important contemporaneous impacts allowed an interpretation of financial interrelations in terms of causality: The short-term interest rates were found to support the value of the domestic currencies, apart from few exceptions. For the better part, the central banks should thus be able to stabilise the exchange rates of their countries. Expectedly, the examination suggests, that most monetary authorities indeed exploit this opportunity by reacting to currency fluctuations. Despite the official classification as free floating, accordingly many exchange rate regimes seem still to be regulated in some sense. One reason might be found in the stock markets, of which the majority obviously prefers stable foreign exchanges to the export advantages of depreciating tendencies. Opposingly, the evidence of money market rate influences on the stock market is mixed: In one group of countries the straightforward negative effect prevails, but the equity prices in another group rather seem to pick up the growth signals of rising interest rates. At last, the appreciating propagation of positive equity shocks into the foreign exchange market and the hardly relevant central bank reactions to such disturbances do not come as a surprise.

Addressing the coherence of shocks in the Asian Pacific region, striking results could be established: The highest correlations belong to the stock market residuals, suggesting that growth innovations are fairly symmetric across the region. In contrast, international money market linkages did not become evident. The foreign exchange markets revealed clear signs of commonalities, at least for a cluster of economies.

Major actual political tasks in the Asian Pacific region include the stabilisation of the financial system, the organisation of the future currency management and the backing of sustained economic development. This research could give valuable information for all these points. Future research might for example consider the task, if structural breaks like the Asian financial crisis can be picked up by the variance process maintaining the assumption of parameter constancy. A further type of interesting applications would be given by including variables of different countries into one structural EGARCH model, in order to address the international linkages directly. In this context, certain common factors could be considered as an additional feature. 


\section{References}

[1] Andersen, T.G., T. Bollerslev, F.X. Diebold, C. Vega (2005): Real-Time Price Discovery in Stock, Bond and Foreign Exchange Markets. NBER Working Paper W11312.

[2] Bautista, C.C. (2003): Interest Rate-Exchange Rate Dynamics in the Philippines: A DCC Analysis. Applied Economics Letters, 10, 107-111.

[3] Berndt, E., B. Hall, R. Hall, J. Hausman (1974): Estimation and Inference in Nonlinear Structural Models. Annals of Social Measurement, 3, 653-665.

[4] Bollerslev, T., J.M. Wooldridge (1992): Quasi-Maximum Likelihood Estimation and Inference in Dynamic Models with Time Varying Covariances. Econometric Reviews, $11,143-172$.

[5] Boyd, J.H., J. Hu, R. Jagannathan (2005): The Stock Market's Reaction to Unemployment News: Why Bad News Is Usually Good for Stocks. The Journal of Finance, 60, 649-672.

[6] Cappiello, L., R.A. De Santis (2005): Explaining exchange rate dynamics: The uncovered equity return parity condition. ECB Working Paper 529.

[7] Caporale, G.M., A. Cipollini, P.O. Demetriades (2005): Monetary policy and the exchange rate during the Asian crisis: identification through heteroscedasticity. Journal of International Money and Finance, 24, 39-53.

[8] Comte, F., O. Lieberman (2003): Asymptotic Theory for Multivariate GARCH Processes. Journal of Multivariate Analysis, 84, 61-84.

[9] Dickey, D.A., W.A. Fuller (1979): Distribution of the Estimators for Autoregressive Time Series with a Unit Root. Journal of the American Statistical Association, 74, 427-431.

[10] Doornik, J.A. (1996): Testing vector error autocorrelation and heteroscedasticity. Unpublished paper, Nullfield College.

[11] Doornik, J.A. (1998): Approximations to the asymptotic distributions of cointegration tests. Journal of Economic Surveys, 12, 573-593.

[12] Johansen, S. (1994): The role of the constant and linear terms in cointegration analysis of nonstationary time series. Econometric Reviews, 13, 205-231. 
[13] Johansen, S. (1995): Likelihood-based Inference in Cointegrated Vector Autoregressive Models. Oxford University Press, Oxford.

[14] MacKinnon, J.G. (1991): Critical Values for Cointegration Tests. Chapter 13 in R.F. Engle, Granger, C.W.J. (eds.): Long-run Economic Relationships: Readings in Cointegration, Oxford University Press, Oxford.

[15] MacKinnon, J.G. (1996): Numerical Distribution Functions for Unit Root and Cointegration Tests. Journal of Applied Econometrics, 11, 601-618.

[16] Lee, K.Y. (2006): The contemporaneous interactions between the U.S., Japan, and Hong Kong stock markets. Economics Letters, 90, 21-27.

[17] Nelson, D.B. (1991): Conditional Heteroskedasticity in Asset Returns: A New Approach. Econometrica, 59, 347-370.

[18] Rigobon, R. (2003): Identification through heteroscedasticity. Review of Economics and Statistics, 85, 777-792.

[19] Rigobon, R., B. Sack (2003a): Measuring the reaction of monetary policy to the stock market. Quarterly Journal of Economics, 118, 639-669.

[20] Rigobon, R., B. Sack (2003b): Spillovers across U.S. financial markets. Working Paper, Sloan School of Management, MIT and NBER.

[21] Stiglitz, J.E. (1999): Interest rates, risk, and imperfect markets: puzzles and policies. Oxford Review of Economic Policy, 15, 59-76. 


\section{Appendix}
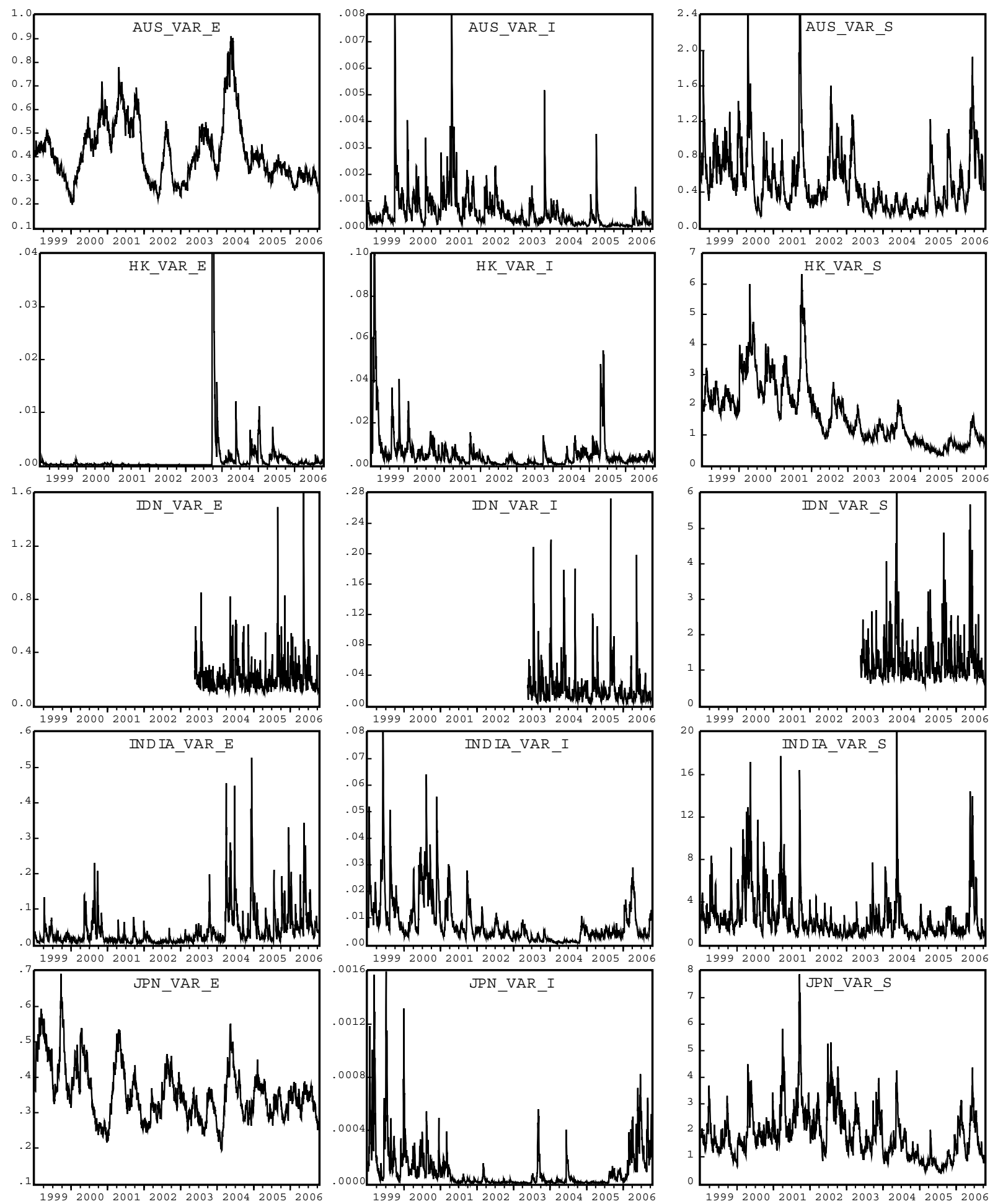

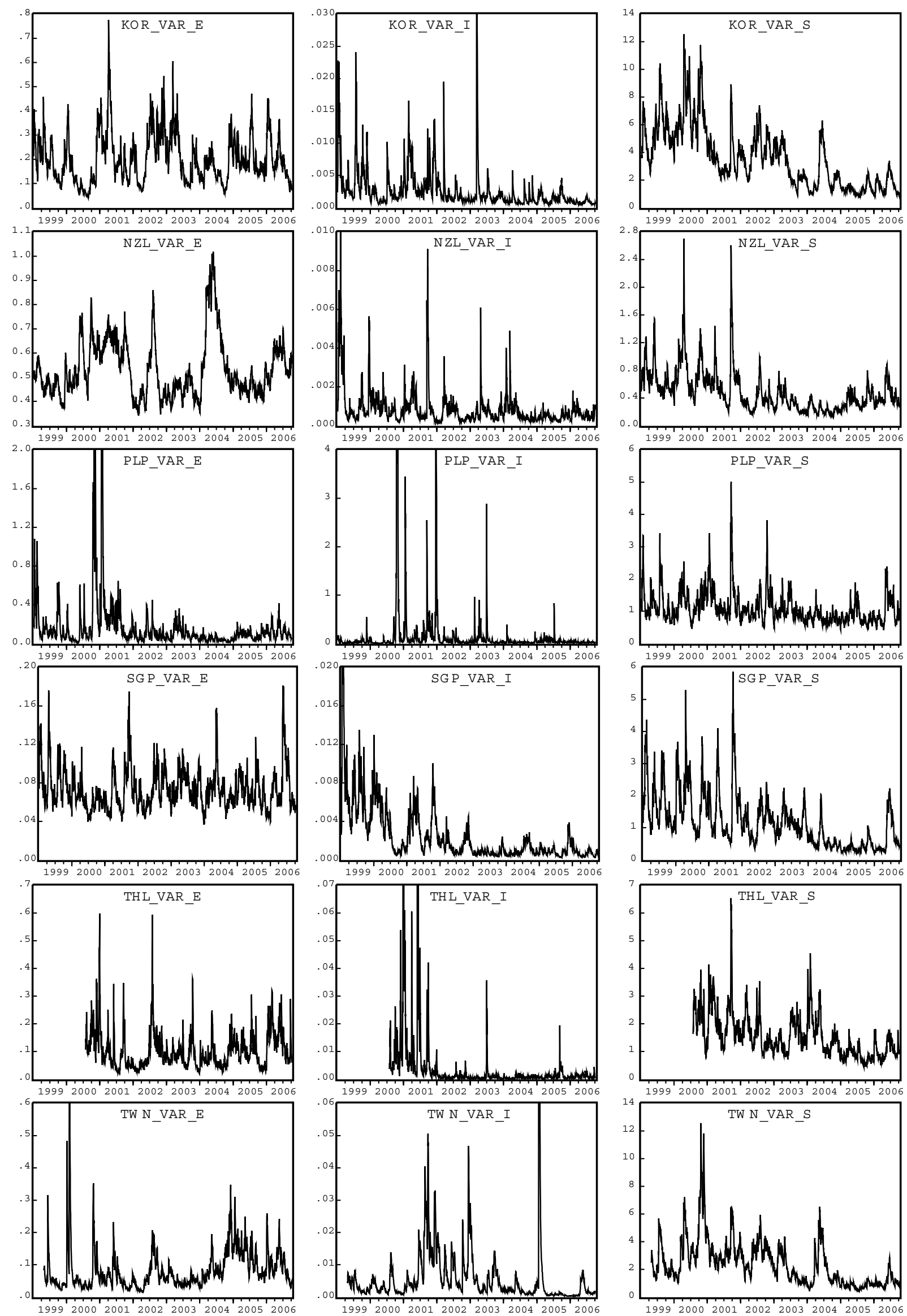

Figure 2: Conditional variances of foreign exchange, money and stock market innovations 


\section{SFB 649 Discussion Paper Series 2007}

For a complete list of Discussion Papers published by the SFB 649, please visit http://sfb649. wiwi. hu-berlin.de.

001 "Trade Liberalisation, Process and Product Innovation, and Relative Skill Demand" by Sebastian Braun, January 2007.

002 "Robust Risk Management. Accounting for Nonstationarity and Heavy Tails" by Ying Chen and Vladimir Spokoiny, January 2007.

003 "Explaining Asset Prices with External Habits and Wage Rigidities in a DSGE Model." by Harald Uhlig, January 2007.

004 "Volatility and Causality in Asia Pacific Financial Markets" by Enzo Weber, January 2007.

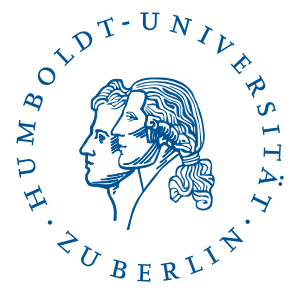

